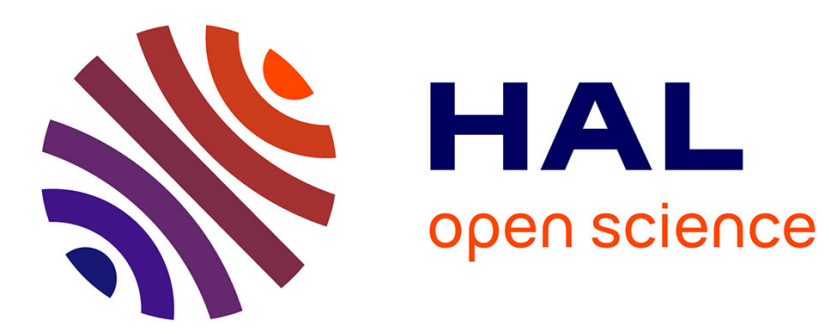

\title{
Non-classical actions of the mineralocorticoid receptor: Misuse of EGF receptors?
}

\author{
Claudia Grossmann, Michael Gekle
}

\section{To cite this version:}

Claudia Grossmann, Michael Gekle. Non-classical actions of the mineralocorticoid receptor: Misuse of EGF receptors?. Molecular and Cellular Endocrinology, 2007, 277 (1-2), pp.6. 10.1016/j.mce.2007.07.001 . hal-00531940

\section{HAL Id: hal-00531940 \\ https://hal.science/hal-00531940}

Submitted on 4 Nov 2010

HAL is a multi-disciplinary open access archive for the deposit and dissemination of scientific research documents, whether they are published or not. The documents may come from teaching and research institutions in France or abroad, or from public or private research centers.
L'archive ouverte pluridisciplinaire HAL, est destinée au dépôt et à la diffusion de documents scientifiques de niveau recherche, publiés ou non, émanant des établissements d'enseignement et de recherche français ou étrangers, des laboratoires publics ou privés. 


\section{Accepted Manuscript}

Title: Non-classical actions of the mineralocorticoid receptor: Misuse of EGF receptors?

Authors: Claudia Grossmann, Michael Gekle

PII: $\quad$ S0303-7207(07)00256-0

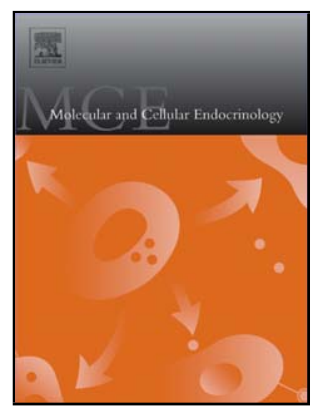

DOI: doi:10.1016/j.mce.2007.07.001

Reference: MCE 6677

To appear in: $\quad$ Molecular and Cellular Endocrinology

Received date: $\quad 25-5-2007$

Revised date: $\quad 18-6-2007$

Accepted date: $\quad$ 2-7-2007

Please cite this article as: Grossmann, C., Gekle, M., Non-classical actions of the mineralocorticoid receptor: Misuse of EGF receptors?, Molecular and Cellular Endocrinology (2007), doi:10.1016/j.mce.2007.07.001

This is a PDF file of an unedited manuscript that has been accepted for publication. As a service to our customers we are providing this early version of the manuscript. The manuscript will undergo copyediting, typesetting, and review of the resulting proof before it is published in its final form. Please note that during the production process errors may be discovered which could affect the content, and all legal disclaimers that apply to the journal pertain. 


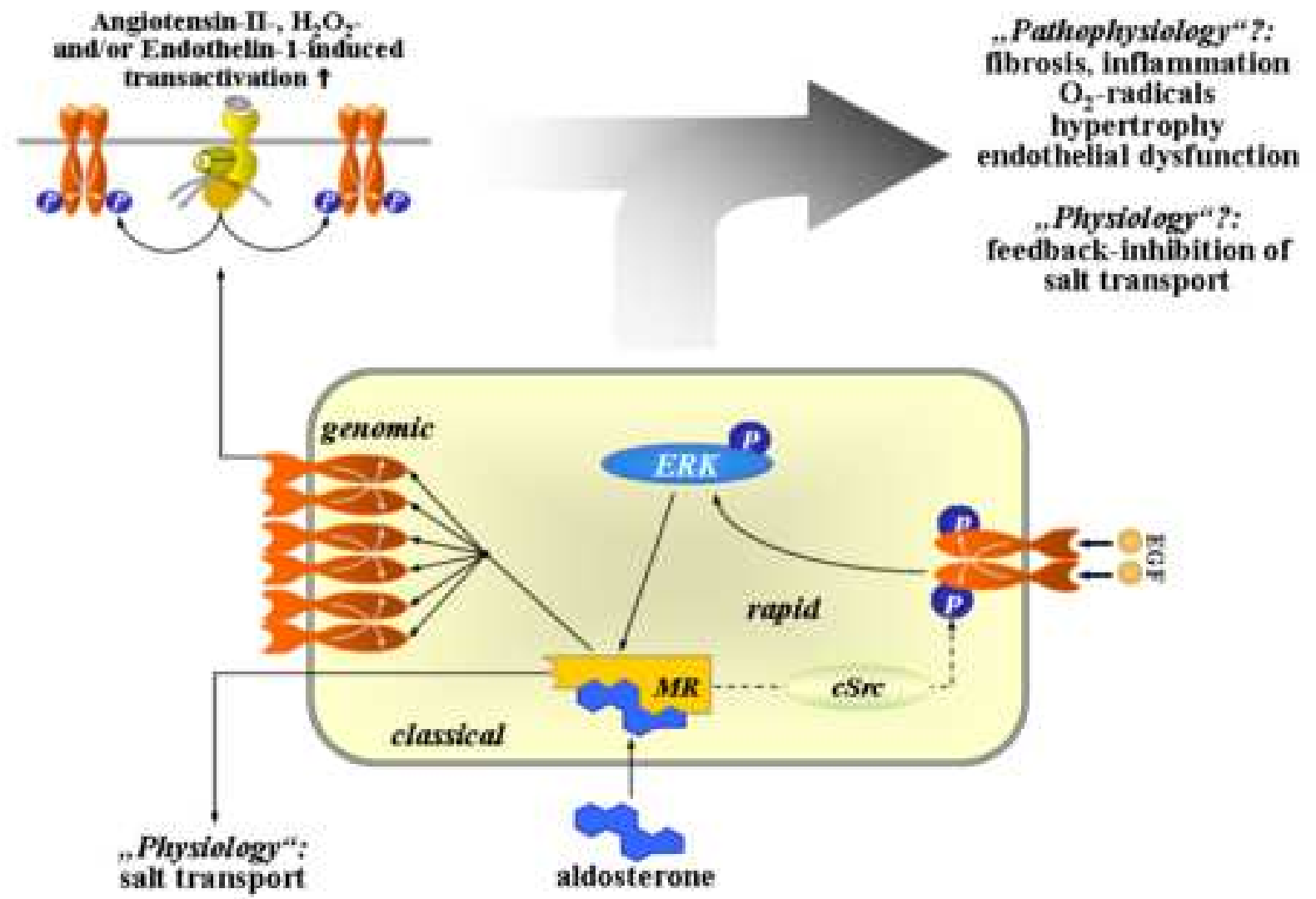


Non-classical actions of the mineralocorticoid receptor: Misuse of EGF receptors?

Claudia Grossmann ${ }^{1}$ and Michael Gekle ${ }^{1}$

${ }^{1}$ Julius-Bernstein-Institut für Physiologie der Universität Halle-Wittenberg, Halle, Germany

Running title: Interaction Between hMR and EGFR Promoter

Address of correspondence to: Michael Gekle, Julius-Bernstein-Institut für Physiologie, Universität Halle-Wittenberg, Magdeburger Strasse 6, 06097 Halle (Saale), Germany, Tel.: ++49 345 557 1886; Fax: ++49 345557 4019; E-mail: michael.gekle@medizin.uni-halle.de 


\begin{abstract}
The mineralocorticoid receptor (MR) plays a key role in cardiovascular and renal injury. The underlying mechanisms seem to involve the epidermal growth factor receptor (EGFR) for the development of fibrosis and vascular dysfunction. Both enhanced EGFR transactivation by activated MR as well as upregulation of EGFR expression by aldosterone-bound MR have been described. While the former seems to be mediated by the tyrosine kinase $\mathrm{cSrc}$, reporter gene assays and chromatin immunoprecipitation data indicate that the latter is caused by an interaction between MR and the EGFR promoter. Pharmacological inhibition of EGFR function prevents some of MR's pathological actions in cell culture systems, like vascular smooth muscle cells. Thus, transactivation as well as enhanced expression of EGFR may be an important switch for the pathophysiological actions in the reno-cardiovascular continuum. Furthermore, EGFR signaling may serve as a negative feedback loop to limit sodium retention. Overall, MR's "misuse" of the EGFR is one possible explanation for the pathophysiological effects of aldosterone, making the EGFR a potential target for therapeutical interventions against reno-cardiovascular remodelling.
\end{abstract}




\section{Classical and non-classical effects of the mineralocorticoid receptor and aldosterone}

Aldosterone is a steroid hormone and the main mineralocorticoid in humans. It is secreted by the zona glomerulosa of the adrenal cortex and for a long time was thought to be primarily involved in electrolyte and volume homeostasis. These classical actions of aldosterone have been mostly studied in the distal nephron and collecting duct of the kidney in the so-called principal cells, responsible for sodium reabsorption and potassium secretion. Aldosterone enters the principal cells presumably by diffusion and bind to its receptor, the mineralocorticoid receptor (MR), located mainly in the cytosol tethered to a heteromeric complex containing hsp90 and other chaperone molecules (Arriza et al., 1987; Funder, 2006). Upon hormone binding, the MR dissociates from this complex, forms homodimers and translocates to the nucleus where it acts as a ligand-induced transcription factor, binding to response elements and modulating the expression of aldosterone-sensitive genes. So far, no mineralocorticoid receptor specific promoter elements have been described and the only binding sites known are shared between the glucocorticoid receptor and the mineralocorticoid receptor and are therefore called glucocorticoid response elements (GRE). In the case of principal cells, the epithelial sodium channel $(\mathrm{ENaC})$, potassium channel $\mathrm{ROMK}, \mathrm{Na}^{+} / \mathrm{K}^{+}-\mathrm{ATPase}$ and mitochondrial enzymes are known targets of MR regulation. The cellular response - sodium reabsorption and potassium secretion eventually leads to systemic alterations, like salt and water retention, enhanced blood pressure, hypokalemia and alkalosis. Similar mechanisms of action also occur in other tight epithelia, like the colon or sweat glands. As T.L. Goodfriend nicely summarized (Goodfriend, 2006) these effects of aldosterone ,... allows humans and animals to live on dry land and eat each other."

MR also can be occupied and at least partially activated by glucocorticoids, which circulate at much higher concentrations than aldosterone but bind with similar affinities. In epithelial tissue MR is protected from glucocorticoids by $11 \beta$ hydroxysteroid dehydrogenase 2 leading to a relative aldosterone selectivity. This does not - or only to a much smaller degree - seem to be the case in cardiovascular tissue where the extent and mechanism of MR selectivity is not completely understood (Funder, 2004; Funder, 2006; Funder, 2006). Thus, studies using socalled "aldosterone antagonists" (which are MR blockers) in vivo in order to explore cardiovascular pathophysiology, investigate, strictly speaking, the effect of activated MR, be it by aldosterone or glucocorticoids. Because aldosterone has a very low affinity for the glucocorticoid receptor (GR) it is generally used to generate situations where MR but not GR is activated.

Recently, evidence has been accumulating that activated MR can elicit additional, nonclassical effects. Besides experimental data, clinical studies like RALES, EPHESUS and 4E (Pitt et al., 1999; Pitt et al., 2003; Pitt, 2003) convincingly demonstrate that mineralocorticoid receptor antagonism protects against cardiovascular and renal remodeling independently of major alterations in blood pressure or $\mathrm{NaCl}$ homeostasis. One classical effect observed in these studies however, was an elevation of serum $\left[\mathrm{K}^{+}\right]$. The model derived from these clinical trials and experimental animal studies, suggests that activated mineralocorticoid receptor induces an inflammatory milieu with enhanced formation of reactive oxygen species and matrix proteins in the vasculature (Rocha et al., 2002; Virdis et al., 2002; Brilla et al., 1992; Zannad et al., 2000). Subsequently, this vasculopathy leads to cardiac and renal damage. Although, this model is now widely accepted, the individual steps in this pathophysiological network are only incompletely understood.

Besides the non-classical actions mediated via the traditional genomic signaling pathway, there are also reports about rapid aldosterone effects that do not involve RNA or protein synthesis and are therefore termed non-genotropic actions. These effects have been characterized in classical and non-classical MR target organs and involve a number of different signaling 
pathways including PKC, PI3-kinase and activation of transporters and pumps like NHE or Na-K-2Cl-cotransporter (Doolan et al., 1996; Mihailidou et al., 2004; Liu et al., 2003; Gekle et al., 2001). However, the overall pathophysiological relevance of these rapid aldosterone actions is only beginning to emerge.

\section{Why the EGF receptor?}

How does the EGF receptor (EGFR) become involved in this scheme? It is known that EGFR promotes renal and cardiovascular fibrosis under certain conditions (Terzi et al., 2000; Flamant et al., 2003; Kagiyama et al., 2003). Furthermore, the profibrotic actions of angtiotensin II (AII) and endothelin-1 (ET-1) depend on EGFR as a relay station (Bokemeyer et al., 2000; Thomas et al., 2002; Asakura et al., 2002; Kagiyama et al., 2002; Flamant et al., 2003). Binding of these two hormones to their cognate receptors leads to activation of EGFR without addition of exogenous ligands, a mechanism denominated EGFR transactivation (Prenzel et al., 1999; Hackel et al., 1999; Shah et al., 2003). It is only through this transactivation that AII or ET-1 are able to activate the kinase ERK1/2 and finally induce renal and cardiovascular damage. For example, Ang II-induced cardiac remodelling in rats and vascular smooth muscle cells (VSMCs) is attenuated by EGFR antisense oligodeoxynucleotides (Kagiyama et al., 2003; Flamant et al., 2003; Hackel et al., 1999; Moghal et al., 1999). In addition, the pathophysiological actions of AII and ET-1 are at least in part related to aldosterone and the mineralocorticoid receptor (Pu et al., 2003; Park et al., 2001; Jaffe et al., 2005; Min et al., 2005). Finally, reports exist that activation of MR enhance the EGF sensitivity of vessels with respect to their contractility (Florian et al., 2001). On the contrary, mineralocorticoid receptor antagonists lower EGFR mRNA levels and prevent remodelling of cerebral vasculature after ischemia (Dorrance et al., 2001). Combining all these data with our knowledge on the pathophysiological, non-classical actions of MR two hypotheses can be formulated respectively two questions can be asked: (i) Does MR activated by aldosterone induce EGFR transactivation and/or (ii) EGFR expression?

\section{First indications of aldosterone-induced EGFR transactivation}

Some years ago we investigated rapid effects of aldosterone on ERK1/2 activation in an epithelial cell line, MDCK cells (Krug et al., 2002; Gekle et al., 2002; Gekle et al., 2002; Gekle et al., 2001), and observed that aldosterone induced a (5-10 $\mathrm{min}$ ) rapid activation of ERK1/2 and a rapid increase of EGFR phosphorylation indicating EGFR transactivation. Furthermore, ERK1/2 activation was prevented by pharmacological blockade of EGFR kinase activity. Additionally, this EGFR transactivation was a prerequisite for other rapid effects of aldosterone, like activation of $\mathrm{Na}^{+} / \mathrm{H}^{+}$-exchanger-1 (Gekle et al., 2001; Gekle et al., 2002). From these data we concluded that aldosterone uses (or misuses) EGFR transactivation for some of its rapid actions. However, we had no information about the link between aldosterone and EGFR.

Subsequently, the possible role of EGFR in rapid aldosterone signaling in vascular smooth muscle and endothelial cells was investigated using pharmacological tools (Mazak et al., 2004; Min et al., 2005; Sugiyama et al., 2005). These studies confirmed our working model of aldosterone-induced EGFR transactivation and provided strong pharmacological evidence for the mineralocorticoid receptor as one missing link between aldosterone and EGFR. For example, activation of ERK1/2 was prevented by MR antagonists or inhibition of EGFR kinase. Moreover, these studies also emphasize the possible pathophysiological relevance of EGFR transactivation. 


\section{Confirmation of aldosterone-induced EGFR transactivation and a role for cSrc}

To test the hypothesis of aldosterone/MR-induced EGFR transactivation further we employed a heterologous expression system (Grossmann et al., 2005). In cells without detectable expression of MR either functionally (GRE-reporter assay) or on the mRNA and protein level (CHO cells, HEK cells), aldosterone elicited no response with respect to ERK1/2 activation (Grossmann et al., 2005; Krug et al., 2002). After transfection with the human MR, the cells showed a genomic response to aldosterone as well as rapid activation of the kinases ERK $1 / 2$ and JNK (Grossmann et al., 2005). Aldosterone induced ERK1/2 activation was prevented by two different pharmacological inhibitors of EGFR kinase, AG1478 and AG112, and by the MR antagonist spironolactone. While protein kinase $\mathrm{C}$ inhibition was not effective, pharmacological inhibition of the cytosolic tyrosine kinase cSrc - known to be involved in EGFR transactivation in various scenarios - prevented the rapid effect of aldosterone (Hackel et al., 1999; Hunyady et al., 2006; Neithardt et al., 2006; Pullar et al., 2006; Wetzker et al., 2003). Likewise, aldosterone stimulated EGFR and cSrc tyrosine phosphorylation, indicating activation of these two kinases.

Studies by Callera et al. (Callera et al., 2005; Callera et al., 2005) and Braun et al. (Braun et al., 2004) also suggest the involvement of $\mathrm{cSrc}$ in rapid aldosterone signaling. Braun et al. showed the spironolactone-sensitive stimulation of cSrc kinase activity in M1 cells. Callera et al. detected a dose-dependent increase in cSrc tyrosine phosphorylation in vascular smooth muscle cells. Furthermore, they showed that aldosterone-induced proliferation of vascular smooth muscle cells could be prevented by inhibition of cSrc or ERK1/2. Thus, aldosterone induced EGFR transactivation involves MR and cSrc, whereas activation of cSrc by aldosterone requires MR expression.

Coming back to the two questions asked, we can give a response to the first one: Aldosterone induces EGFR transactivation via the mineralocorticoid receptor and the tyrosine kinase cSrc. This mechanism of action is mineralocorticoid receptor specific and of potential importance for pathophysiological effects of aldosterone.

\section{First indications of aldosterone-induced EGFR expression}

In addition to aldosterone-induced EGFR transactivation in cell culture, pharmacological in vivo studies show that MR activation enhances EGF-induced contraction of arteries (Florian et al., 2001) and that the MR antagonist spironolactone reduces the expression of EGFR mRNA after cerebral ischemia (Dorrance et al., 2001). Furthermore, a MR-dependent increase of EGFR mRNA or protein in cardiovascular tissue has been reported (Nakano et al., 2005; Northcott et al., 2001). When we investigated EGFR expression on the protein level in adrenalectomized rats, we observed a stimulation of EGFR expression by aldosterone in the aorta, heart and kidney but not in liver or adipose tissue (Grossmann et al., 2007). Additionally, aldosterone enhanced EGFR expression in cultured kidney cells (Grossmann et al., 2004; Krug et al., 2003) and cultured human vascular smooth muscle cells (Grossmann et al., 2007), an effect that could be prevented by spironolactone. Thus, aldosterone has the potential to stimulate EGFR expression through a MR-dependent mechanism under certain conditions.

\section{Molecular mechanisms of aldosterone-induced EGFR expression}

To test the hypothesis of aldosterone/MR induced EGFR expression further we again employed our heterologous expression system (Krug et al., 2003). CHO cells which showed no detectable expression of MR or EGFR elicited no response to aldosterone with respect to EGFR expression (Krug et al., 2003). After transfection with the human MR, the cells re- 
sponded to aldosterone with enhanced EGFR expression in the absence but not in the presence of spironolactone. Tranfection of the human glucocorticoid receptor (GR) did not effect EGFR expression. In agreement with these data, aldosterone stimulated the EGFR promoter only in cell expressing MR while GR expressing cells showed no alterations in EGFR expression in the presence of dexamethasone or aldosterone. EGFR activation by aldosterone/MR was concentration dependent with an $\mathrm{EC}_{50}$ value of $\sim 0.5 \mathrm{nmol} / 1$. These data demonstrate that aldosterone/MR but not GR stimulate EGFR expression, at least in part by activation of the EGFR promoter. There are no indications for altered mRNA or protein stability. However, the data so far do not allow discriminating between a direct MR/EGFR-promoter interaction and an indirect one, although experiments applying the chromatin immunoprecipitation (ChIP) technique suggest a direct binding of MR to the EGFR promoter or at least to DNA sites close to the promoter (Grossmann et al., 2007).

More detailed EGFR promoter analysis revealed that there are two domains of interaction with the MR (Grossmann et al., 2007). One domain is located in the region -1 to -163 adjacent to the transcription initiation site and the second domain is located in the region -163 to 316. According to reporter gene assays, these interactions occur in the transition range between physiological and clearly pathophysiological aldosterone concentrations $\left(\mathrm{EC}_{50} \sim 1\right.$ nmol/l (Grossmann et al., 2007)). Furthermore, the A/B-domain of the MR is required.

Both EGFR promoter interaction domains were insensitive to glucocorticoids/GR. These observations can help to explain the fact that under physiological conditions aldosterone exerts its physiological actions on salt homeostasis but does not induce vasculopathy. Furthermore, this mechanism offers an additional explanation for differential effects of GR and MR.

Coming back to the two questions asked we can now give a response to the second one, as well. Aldosterone induces EGFR expression via the mineralocorticoid receptor. This mechanism is also of potential importance for pathophysiological effects of activated MR because (i) EGFR has been shown to promote pathological tissue alterations and (ii) because activated MR enhances the number of switches for angiotensin II and endothelin-1.

So far, at least three tracks of cellular aldosterone signaling have been described and therefore have to be considered (Grossmann et al., 2005). Besides the classical, MR-dependent, genomic track, leading to the expression of so-called aldosterone-induced proteins like the EGFR, we have a rapid, nongenotropic but MR-dependent track, leading to the activation of, at least, ERK1/2- and JNK1/2-kinase. This nongenotropic, MR-dependent signaling track seems to involve cSrc and EGFR, similar to the mechanisms described for other steroid hormone receptors (Boonyaratanakornkit et al., 2001; Migliaccio et al., 1998; Migliaccio et al., 2000). Despite the still missing mechanistic details, it is now clear that the classical MR rather than an alternative membrane aldosterone receptor contributes to rapid signaling as already known from other steroid receptors. Finally, there is an ill-defined nongenotropic, MR-independent track, which nevertheless seems to distinguish between aldosterone and dexamethasone but does not seem to involve the EGFR. There are indications that aldosterone enhances $\mathrm{Ca}^{2+}$-influx by a yet unknown pathways through this mechanism (Grossmann et al., 2005; Gekle et al., 1996). What is still not clear is if these different signaling pathways interact with each other. Le Moellic et al. (Le Moellic et al., 2004) reported that rapid aldosterone-induced PKC-activation supports the genomic track of aldosterone, indicating an interaction between the genomic and nongenotropic signaling tracks. Thus, not only the existence of three signaling tracks, but also the degree of their crosstalk enhances the complexity of aldosterone signaling. Knowledge of the crosstalk between genomic and nongenotropic actions will be critical for our understanding the diverse biologic responses to steroids.

\section{ERK1/2 activation may support genomic actions of MR}


In our heterologous MR expression system (Grossmann et al., 2005) inhibition of ERK1/2 reduced aldosterone-induced transactivation activity at a canonical GRE element. The underlying mechanisms included impaired nuclear-cytoplasmic shuttling of MR. In the presence of an ERK1/2 inhibitor (U0126) translocation of MR into the nucleus was inhibited. Thus, MRdependent nongenotropic actions (ERK1/2 activation) can support the classical, MRdependent, genomic track under certain circumstances. It is currently not known whether MR is phosphorylated by ERK1/2 or whether further adaptor proteins are involved. However, it is known that the control of MR genomic activity by ERK1/2 depends on the N-terminal A/Bdomain of MR. Deletion of these domains turns MR insensitive to ERK1/2 inhibition with respect to the classical transactivation activity at a canonical GRE element (Pfau et al., 2007). The same domains are also required for the modulatory actions of cAMP and $\mathrm{Ca}^{2+}$ (Pfau et al., 2007).

\section{First tests on the possible importance of EGFR for pathophysiological actions of MR}

Because aldosterone/MR enhance EGFR expression in human aortic smooth muscle cells in primary culture, we tested whether the hormone per se, in the presence of EGFR activation (by addition of EGF) or during EGFR transactivation (the presence of $\mathrm{H}_{2} \mathrm{O}_{2}$ ) enhances collagen or fibronectin abundance (Gekle et al., 2007; Grossmann et al., 2007). Aldosterone alone exerted only minor effects but it potentiated the stimulatory action of low concentrations of $\mathrm{H}_{2} \mathrm{O}_{2}$ or of EGF. Inhibition of the EGFR kinase or blockade of MR prevented this potentiation. These data support the hypothesis that EGFR contributes to pathophysiological actions of activated MR. However, the relative importance of transactivation and altered expression still needs to be determined.

In addition to its involvement in pathophysiological effects, EGFR also seems to play a role in the classical regulation of salt transport. For instance, stimulation of EGFR inhibits sodium current via the epithelial sodium channel (ENaC) in C7 and mCT1 cells (Shen et al., 2003; Grossmann et al., 2004). Furthermore, the EGF-signaling pathway can exert a tonic suppressive effect on the action of aldosterone with respect to ENaC (Grossmann et al., 2004). Simultaneously, aldosterone exerts a long term stimulatory effect on the EGF-signaling pathway. Thus, aldosterone stimulates a signaling system (EGFR), which antagonizes the action of aldosterone on salt transport. Furthermore, inhibition of EGFR enhances the action of aldosterone on $\mathrm{ENaC}$. Taken together, these components form a negative feedback loop and allow the hypothesis that the EGF-signaling pathway helps to prevent overstimulation of $\mathrm{Na}^{+}-$ reabsorption by aldosterone.

\section{Conclusions}

Overall, it is becoming increasingly established that aldosterone and the mineralocorticoid receptor elicit non-classical pathophysiological actions either via genomic or nongenotropic signaling pathways in addition to the classical regulation of salt and water homeostasis. One possible interaction partner is the EGFR, which functions as a signal transducer for various G-protein-coupled receptors and is involved in the profibrotic and proliferative effects induced by angiotensin-II and endothelin-1. Recent in vivo and in vitro studies provide strong evidence that there is an interaction between MR and the EGFR signaling pathway, showing both induction of transactivation and induction of expression of the EGFR by slightly supraphysiological concentrations of aldosterone. Therefore, MR's "misuse" of the EGFR could be one explanation for its pathophysiological effects and a potential target for therapeutical intervention against reno-cardiovascular remodeling. 


\section{Acknowledgements}

Work performed in the authors' laboratory was supported by the Deutsche Forschungsgemeinschaft (DFG). 


\section{References}

1. J.L. Arriza, C. Weinberger, G. Cerelli, T.M. Glaser, B.L. Handelin, D.E. Housman and R.M. Evans, Cloning of human mineralocorticoid receptor complementary DNA: structural and functional kinship with the glucocorticoid receptor, Science 237 (1987), pp. 268-275.

2. J.W. Funder, Aldosterone and Mineralocorticoid Receptors. Lessons From Gene Deletion Studies, Hypertension 48 (2006), pp. 1018-1019.

3. T.L. Goodfriend, Aldosterone - a hormone of cardiovascular adaptation and maladaptation., J Clin Hypertens 8 (2006), pp. 133-139.

4. J.W. Funder, Is aldosterone bad for the heart?, Trends in Endocrinology and Metabolism 15 (2004), pp. 139-142.

5. J.W. Funder, Mineralocorticoid Receptors and Cardiovascular Damage. It's Not Just Aldosterone, Hypertension 47 (2006), pp. 634-635.

6. J.W. Funder, Aldosterone and the cardiovascular system: genomic and nongenomic effects, Endocrinology 147 (2006), pp. 5564-5567.

7. B. Pitt, F. Zannad, W.J. Remme, R. Cody, A. Castaigne, A. Perez, J. Palensky and J. Wittes, The effect of spironolactone on morbidity and mortality in patients with severe heart failure. Randomized Aldactone Evaluation Study Investigators, $N$ Engl J Med 341 (1999), pp. 709-717.

8. B. Pitt, W. Remme, F. Zannad et al., Eplerenone, a selective aldosterone blocker, in patients with left ventricular dysfunction after myocardial infarction, $N$ Engl J Med 348 (2003), pp. 1309-1321.

9. B. Pitt, Aldosterone Blockade in Patients With Systolic Left Ventricular Dysfunction, Circulation 108 (2003), pp. 1790-1794.

10. R. Rocha, A.E. Rudolph, G.E. Frierdich, D.A. Nachowiak, B.K. Kekec, E.A.G. Blomme, E.G. McMahon and J.A. Delyani, Aldosterone induces a vascular inflammatory phenotype in the rat heart, AJP - Heart and Circulatory Physiology $\mathbf{2 8 3}$ (2002), pp. H1802-H1810.

11. A. Virdis, M.F. Neves, F. Amiri, E. Viel, R.M. Touyz and E.L. Schiffrin, Spironolactone Improves Angiotensin-Induced Vascular Changes and Oxidative Stress, Hypertension 40 (2002), pp. 504-510.

12. C.G. Brilla and K.T. Weber, Mineralocorticoid excess, dietary sodium, and myocardial fibrosis, J Lab Clin Med 120 (1992), pp. 893-901.

13. F. Zannad, F. Alla, B. Dousset, A. Perez and B. Pitt, Limitation of Excessive Extracellular Matrix Turnover May Contribute to Survival Benefit of Spironolactone Therapy in Patients With Congestive Heart Failure : Insights From the Randomized Aldactone Evaluation Study (RALES), Circulation 102 (2000), pp. 2700-2706. 
14. C.M. Doolan and B.J. Harvey, Modulation of cytosolic protein kinase C and calcium ion activity by steroid hormones in rat distal colon., J Biol Chem 271 (1996), pp. 8763-8767.

15. A.S. Mihailidou, M. Mardini and J.W. Funder, Rapid, Nongenomic Effects of Aldosterone in the Heart Mediated by $\varepsilon$ Protein Kinase C, Endocrinology 145 (2004), pp. 773-780.

16. S.L. Liu, S. Schmuck, J.Z. Chorazcyzewski, R. Gros and R.D. Feldman, Aldosterone Regulates Vascular Reactivity: Short-Term Effects Mediated by Phosphatidylinositol 3-Kinase-Dependent Nitric Oxide Synthase Activation, Circulation 108 (2003), pp. 2400-2406.

17. M. Gekle, R. Freudinger, S. Mildenberger, K. Schenk, I. Marschitz and H. Schramek, Rapid activation of $\mathrm{Na}^{+} / \mathrm{H}^{+}$-exchange in MDCK-cells by aldosterone involves MAPkinases ERK1/2., Pflügers Arch 441 (2001), pp. 781-786.

18. F. Terzi, M. Burtin, M. Hekmati, P. Federici, G. Grimber, P. Briand and G. Friedlander, Targeted expression of a dominant-negative EGF-R in the kidney reduces tubulo-interstitial lesions after renal injury, J Clin Invest 106 (2000), pp. 225-234.

19. M. Flamant, P.L. Tharaux, S. Placier, D. Henrion, T. Coffman, C. Chatziantoniou and J.C. Dussaule, Epidermal growth factor receptor transactivation mediates the tonic and fibrogenic effects of endothelin in the aortic wall of transgenic mice, FASEB J 17 (2003), pp. 327-329.

20. S. Kagiyama, K. Qian, T. Kagiyama and M.I. Phillips, Antisense to epidermal growth factor receptor prevents the development of left ventricular hypertrophy, Hypertension 41 (2003), pp. 824-829.

21. D. Bokemeyer, U. Schmitz and H.J. Kramer, Angiotensin II-induced growth of vascular smooth muscle cells requires an Src-dependent activation of the epidermal growth factor receptor, Kidney Int 58 (2000), pp. 549-558.

22. W.G. Thomas, Y. Brandenburger, D.J. Autelitano, T. Pham, H. Qian and R.D. Hannan, Adenoviral-Directed Expression of the Type 1A Angiotensin Receptor Promotes Cardiomyocyte Hypertrophy via Transactivation of the Epidermal Growth Factor Receptor, Circ Res 90 (2002), pp. 135-142.

23. M. Asakura, M. Kitakaze, S. Takashima et al., Cardiac hypertrophy is inhibited by antagonism of ADAM12 processing of HB-EGF: metalloproteinase inhibitors as a new therapy, Nat Med 8 (2002), pp. 35-40.

24. S. Kagiyama, S. Eguchi, G.D. Frank, T. Inagami, Y.C. Zhang and M.I. Phillips, Angiotensin II-Induced Cardiac Hypertrophy and Hypertension Are Attenuated by Epidermal Growth Factor Receptor Antisense, Circulation 106 (2002), pp. 909-912.

25. N. Prenzel, E. Zwick, H. Daub, M. Leserer, R. Abraham, C. Wallasch and A. Ullrich, EGF receptor transactivation by G-protein-coupled receptors requires metalloproteinase cleavage of proHB-EGF, Nature 402 (1999), pp. 884-888. 
26. P.O. Hackel, E. Zwick, N. Prenzel and A. Ullrich, Epidermal growth factor receptors: critical mediators of multiple receptor pathways., Curr Opin Cell Biol 11 (1999), pp. 184-189.

27. B.H. Shah and K.J. Catt, A central role of EGF receptor transactivation in angiotensin II -induced cardiac hypertrophy, Trends in Pharmacological Sciences 24 (2003), pp. 239-244.

28. N. Moghal and P.W. Sternberg, Multiple positive and negative regulators of signaling by the EGF-receptor., Curr Opin Cell Biol 11 (1999), pp. 190-196.

29. Q. Pu, M.F. Neves, A. Virdis, R.M. Touyz and E.L. Schiffrin, Endothelin Antagonism on Aldosterone-Induced Oxidative Stress and Vascular Remodeling, Hypertension 42 (2003), pp. 49-55.

30. J.B. Park and E.L. Schiffrin, ETA Receptor Antagonist Prevents Blood Pressure Elevation and Vascular Remodeling in Aldosterone-Infused Rats, Hypertension 37 (2001), pp. 1444-1449.

31. I.Z. Jaffe and M.E. Mendelsohn, Angiotensin II and Aldosterone Regulate Gene Transcription Via Functional Mineralocortocoid Receptors in Human Coronary Artery Smooth Muscle Cells, Circ Res 96 (2005), pp. 643-650.

32. L.J. Min, M. Mogi, J.M. Li, J. Iwanami, M. Iwai and M. Horiuchi, Aldosterone and Angiotensin II Synergistically Induce Mitogenic Response in Vascular Smooth Muscle Cells, Circ Res 97 (2005), pp. 434-442.

33. J.A. Florian, A. Dorrance, R.C. Webb and S.W. Watts, Mineralocorticoids upregulate arterial contraction to epidermal growth factor, Am J Physiol Regul Integr Comp Physiol 281 (2001), pp. R878-R886.

34. A.M. Dorrance, H.L. Osborn, R. Grekin and R.C. Webb, Spironolactone reduces cerebral infarct size and EGF-receptor mRNA in stroke-prone rats, Am J Physiol Regul Integr Comp Physiol 281 (2001), pp. R944-R950.

35. A.W. Krug, C. Schuster, B. Gassner, R. Freudinger, S. Mildenberger, J. Troppmair and M. Gekle, Human EGF receptor 1 (HER1) expression renders CHO cells sensitive to alternative aldosterone signaling., J Biol Chem 277 (2002), pp. 45892-45897.

36. M. Gekle, R. Freudinger, S. Mildenberger and S. Silbernagl, Aldosterone interaction with epidermal growth factor receptor signaling in MDCK cells, Am J Physiol Renal Physiol 282 (2002), pp. F669-F679.

37. M. Gekle, R. Freudinger, S. Mildenberger and S. Silbernagl, Rapid actions of aldosterone on cells from renal epithelium: the possible role of EGF-receptor signaling, Steroids 67 (2002), pp. 499-504.

38. I. Mazak, A. Fiebeler, D.N. Muller et al., Aldosterone Potentiates Angiotensin IIInduced Signaling in Vascular Smooth Muscle Cells, Circulation 109 (2004), pp. 2792-2800. 
39. T. Sugiyama, T. Yoshimoto, K. Tsuchiya, N. Gochou, Y. Hirono, T. Tateno, N. Fukai, M. Shichiri and Y. Hirata, Aldosterone Induces Angiotensin Converting Enzyme Gene Expression via a JAK2-Dependent Pathway in Rat Endothelial Cells, Endocrinology 146 (2005), pp. 3900-3906.

40. C. Grossmann, A. Benesic, A.W. Krug, R. Freudinger, S. Mildenberger, B. Gassner and M. Gekle, Human mineralocorticoid receptor expression renders cells responsive for nongenotropic aldosterone actions, Molecular Endocrinology 19 (2005), pp. 1697 1710 .

41. L. Hunyady and K.J. Catt, Pleiotropic AT1 Receptor Signaling Pathways Mediating Physiological and Pathogenic Actions of Angiotensin II, Molecular Endocrinology 20 (2006), pp. 953-970.

42. A. Neithardt, M.P. Farshori, F.B. Shah, K.J. Catt and B.H. Shah, Dependence of GnRH-induced phosphorylation of CREB and BAD on EGF receptor transactivation in GT1-7 neuronal cells, J Cell Physiol 208 (2006), pp. 586-593.

43. C.E. Pullar and R.R. Isseroff, The \{beta 2 -adrenergic receptor activates promigratory and pro-proliferative pathways in dermal fibroblasts via divergent mechanisms, J Cell Sci 119 (2006), pp. 592-602.

44. R. Wetzker and F.D. Bohmer, Transactivation joins multiple tracks to the ERK/MAPK cascade, Nat Rev Mol Cell Biol 4 (2003), pp. 651-657.

45. G.E. Callera, R.M. Touyz, R.C. Tostes, A. Yogi, Y. He, S. Malkinson and E.L. Schiffrin, Aldosterone Activates Vascular p38MAP Kinase and NADPH Oxidase Via cSrc, Hypertension 45 (2005), pp. 773-779.

46. G.E. Callera, A.C.I. Montezano, A. Yogi, R.C. Tostes, Y. He, E.L. Schiffrin and R.M. Touyz, c-Src-Dependent Nongenomic Signaling Responses to Aldosterone Are Increased in Vascular Myocytes From Spontaneously Hypertensive Rats, Hypertension 46 (2005), pp. 1032-1038.

47. S. Braun, R.M. Lösel, M. Wehling and B. Boldyreff, Aldosterone rapidly activates Src kinase in M-1 cells involving the mineralocorticoid receptor and HSP84, FEBS Lett 570 (2004), pp. 69-72.

48. S. Nakano, N. Kobayashi, K. Yoshida, T. Ohno and H. Matsuoka, Cardioprotective mechanisms of spironolactone associated with the angiotensin-converting enzyme/epidermal growth factor receptor/extracellular signal-regulated kinases, $\mathrm{NAD}(\mathrm{P}) \mathrm{H}$ oxidase/lectin-like oxidized low-density lipoprotein receptor-1, and Rhokinase pathways in aldosterone/salt-induced hypertensive rats, Hypertens Res $\mathbf{2 8}$ (2005), pp. 925-936.

49. C. Northcott, J.A. Florian, A. Dorrance and S.W. Watts, Arterial Epidermal Growth Factor Receptor Expression in Deoxycorticosterone Acetate-Salt Hypertension, $\mathrm{Hy}$ pertension 38 (2001), pp. 1337-1341.

50. C. Grossmann, A.W. Krug, R. Freudinger, S. Mildenberger, K. Volker and M. Gekle, Aldosterone-induced Epidermal Growth Factor Receptor (EGFR) expression: Interac- 
tion Between the Human Mineralocorticoid Receptor and the Human EGFR Promoter, Am J Physiol Endocrinol Metab 292 (2007), pp. 1790-1800.

51. C. Grossmann, R. Freudinger, S. Mildenberger, A.W. Krug and M. Gekle, Evidence for epidermal growth factor receptor as negative-feedback control in aldosteroneinduced $\mathrm{Na}^{+}$reabsorption, Am J Physiol Renal Physiol 286 (2004), pp. F1226-F1231.

52. A.W. Krug, C. Grossmann, C. Schuster, R. Freudinger, S. Mildenberger, M.V. Govindan and M. Gekle, Aldosterone stimulates epidermal growth factor receptor (EGFR) expression, J Biol Chem 278 (2003), pp. 43060-43066.

53. V. Boonyaratanakornkit, M.P. Scott, V. Ribon, L. Sherman, S.M. Anderson, J.L. Maller, W.T. Miller and D.P. Edwards, Progesterone receptor contains a proline-rich motif that directly interacts with $\mathrm{SH} 3$ domains and activates c-Src family tyrosine kinases, Mol Cell 8 (2001), pp. 269-280.

54. A. Migliaccio, D. Piccolo, G. Castoria, M. Di Domenico, A. Bilancio, M. Lombardi, W. Gong, M. Beato and F. Auricchio, Activation of the Src/p21ras/Erk pathway by progesterone receptor via cross-talk with estrogen receptor, EMBOJ 17 (1998), pp. 2008-2018.

55. A. Migliaccio, G. Castoria, M. Di Domenico et al., Steroid-induced androgen receptor-oestradiol receptor beta-Src complex triggers prostate cancer cell proliferation, EMBO J 19 (2000), pp. 5406-5417.

56. M. Gekle, N. Golenhofen, H. Oberleithner and S. Silbernagl, Rapid activation of $\mathrm{Na}^{+} / \mathrm{H}^{+}$-exchange by aldosterone in renal epithelial cells requires $\mathrm{Ca}^{2+}$ and stimulation of a plasma membrane proton conductance., Proc Natl Acad Sci USA 93 (1996), pp. 10500-10504.

57. C. Le Moellic, A. Ouvrard-Pascaud, C. Capurro, F. Cluzeaud, M. Fay, F. Jaisser, N. Farman and M. Blot-Chabaud, Early nongenomic events in aldosterone action in renal collecting duct cells: PKCalpha activation, mineralocorticoid receptor phosphorylation, and cross-talk with the genomic response, J Am Soc Nephrol 15 (2004), pp. $1145-1160$.

58. A. Pfau, C. Grossmann, R. Freudinger, S. Mildenberger, A. Benesic and M. Gekle, $\mathrm{Ca}^{2+}$ but not $\mathrm{H} 2 \mathrm{O} 2$ modulates GRE-element activation by the human mineralocorticoid receptor in HEK cells, Mol Cell Endocrinol 264 (2007), pp. 35-43.

59. M. Gekle, S. Mildenberger, R. Freudinger and C. Grossmann, Altered collagen homeostasis in human aortic smooth muscle cells (HAoSMCs) induced by aldosterone, Pflugers Arch 454 (2007), pp. 403-413.

60. J.P. Shen and C.U. Cotton, Epidermal growth factor inhibits amiloride-sensitive sodium absorption in renal collecting duct cells, Am J Physiol Renal Physiol 284 (2003), pp. F57-F64. 


\section{Figure legend}

The classical physiological action of aldosterone is regulation of salt transport via the mineralocorticoid receptor. However, the activated mineralocorticoid receptor can rapidly transactivate the EGF receptor (probably via the cytosolic tyrosine kinase cSrc) resulting in ERK1/2 activation. Furthermore, activated mineralocorticoid receptor can enhance EGFR expression by a genomic mechanism (interaction with EGFR promoter). Increasing the number of EGFR makes a cell more sensitive for transactivating activity of other pathophysiological relevant stimuli, like angiotensin II, endothelin-1 or reactive oxygen species. Rapid activation of ERK1/2 and/or enhanced EGFR expression are possibly important modules in the signaling network responsible for pathophysiological actions of MR (induction of fibrosis and inflammation, formation of $\mathrm{O}_{2}$-radicals, endothelial dysfunction). Furthermore, they may also modulate the classical action of $\mathrm{MR}$, i.e. regulation of salt transport. 